\title{
BLICKDIAGNOSE
}

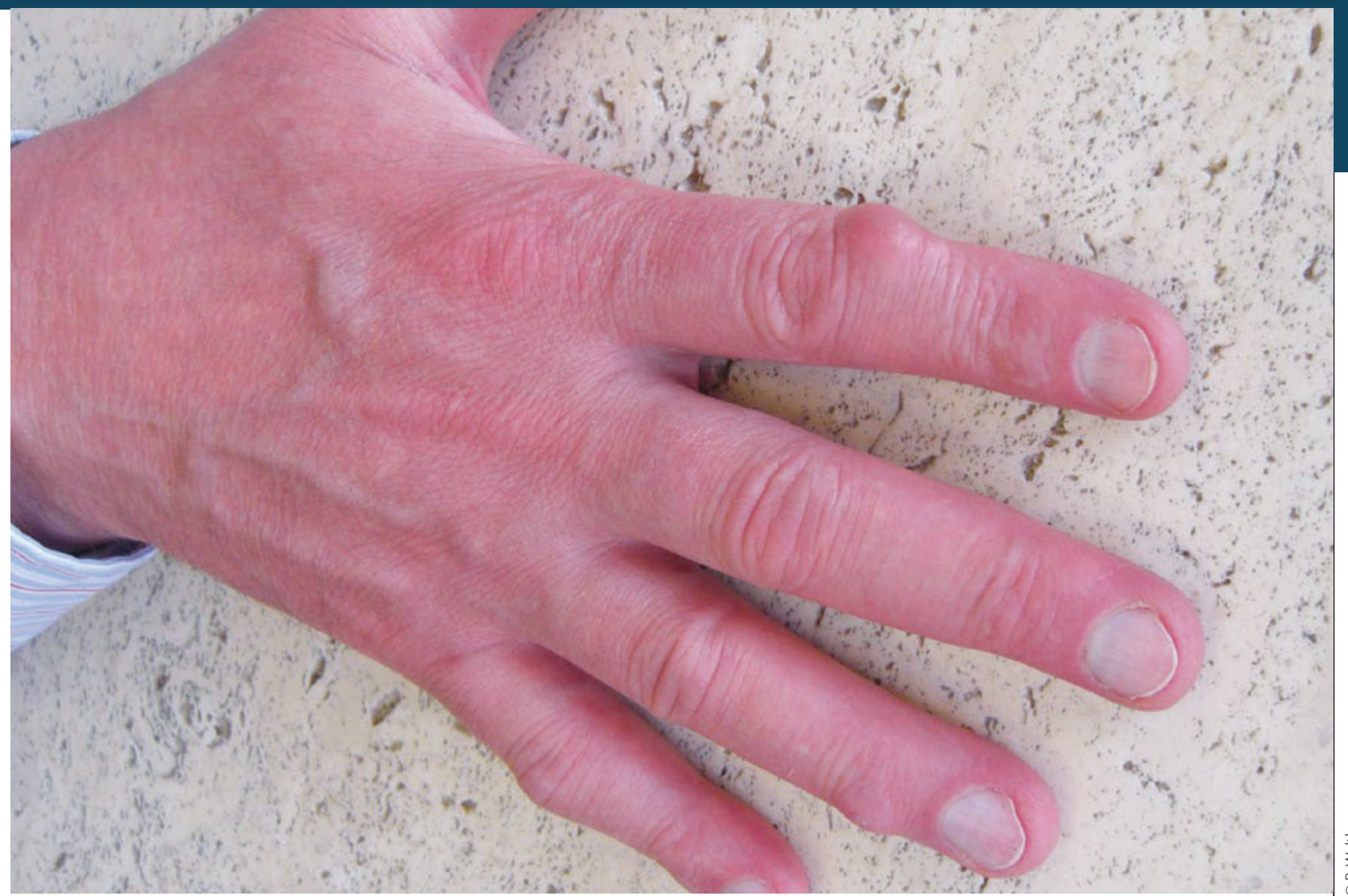

Bei einem 50-Jährigen

\section{Leichte Entzündung und derbe Knoten}

Der 50-jährige Patient schilderte eine relativ mild verlaufende Entzündung der Fingergrundgelenke mit diskreter Morgensteifigkeit. Weiterhin bestehen seit längerem am rechten Zeigefinger und am rechten Ringfinger derbe hautfarbene Knoten.

- In der Laborchemie konnten sowohl ein Rheumafaktor als auch ein CCP-Antikörper nachgewiesen werden. Es liegt hier der Befund typischer Rheumaknoten vor. Rheumaknoten sind ca. 0,5-4 cm groß und treten hauptsächlich an Olecranon, der proximalen Ulna und im Bereich der Achillessehnen auf. Bei ca. 20-30\% der Patienten mit chronischer Polyarthritis kommt es zur Ausbildung dieser Rheumaknoten, allerdings nur bei den seropositiven Fällen. Sie erscheinen fast immer als hautfarbene, derbe Knoten.

Histologisch finden sich palisadenförmig angeordnete Makrophagen, die um eine zentrale Zone nekrotischen
Materials angeordnet sind. Es gibt auch Manifestationen außerhalb der Gelenkbereiche, z. B. in der Lunge. Hier besteht die Differenzialdiagnose zu einem malignen Rundherd. Eine fokale Vaskulitis wird als Ursache der Frühform von Rheumaknoten diskutiert.

Nikotinabusus soll die Ausbildung von Rheumaknoten verstärken. Unter einer Basistherapie mit Methotrexat kann es zu einer deutlichen Zunahme der Rheumaknoten kommen.

Keywords: rheumatic nodules

- Dr. med. B. Walther, Praxis für Innere Medizin, Tal 6, D-80331 München

www.springermedizin.de

Weitere Blickdiagnosen finden Sie im

Internet unter:

http://www.springermedizin.de/blickdiagnose 